\title{
Circulating tumor cells in patients undergoing androgen deprivation therapy with versus without cryosurgery for metastatic prostate cancer: a retrospective analysis
}

\author{
Mingxiong Sheng ${ }^{1,2}$, Shanming Guo ${ }^{2}$ and Chunxiao Liü ${ }^{1 *}$
}

\begin{abstract}
Background: The study aimed to assess the value of circulating tumor cells (CTCS) as a prognostic and treatment response marker in patients undergoing androgen deprivation therapy (ADT) plus cryosurgery vs. ADT alone for metastatic prostate cancer (mPCA).
\end{abstract}

Methods: This retrospective analysis included 43 patients with mPCA: 23 receiving ADT alone (control) and 20 receiving additional cryosurgery (cryosurgery group). CTCs and progression-free survival (PFS) were compared between the two groups. Cox proportional hazards regression was conducted to identify variables associated with PFS.

Results: Median PFS was 35 months (IQR, 33-37) in the cryosurgery group vs. 30 months (IQR, 27-32) in the control ( $p$ $<0.001)$. CTCs count was significantly lower in the cryosurgery group at both 3 months $(z=2.170, p=0.030)$ and 12 months $(z=2.481 ; p=0.013)$. In comparison to the baseline, the number of CTCs at both 3 and 12 months was lower in the cryosurgery group ( $p=0.004$ and $p<0.001$, respectively), but not in the ADT alone group. In multivariate Cox regression, shorter PFS was associated with baseline PSA $\geqq 100 \mathrm{ng} / \mathrm{ml}$ (HR 6.584, 95\% Cl, 5.309-8.166), biopsy Gleason score $\geqq 8$ (HR 2.064, 95\% Cl, 1.608-2.650), clinic T stage>T2b (HR 5.021, 95\% Cl, 3.925-6.421), number of bone metastases $>3$ (HR 3.421, 95\% Cl, 2.786-4.202), positive CTCs at 3 months post-treatment (HR 6.833, 95\% Cl, 5.176-9.022), positive CTCs 1 year post-treatment (HR 6.051, 95\% Cl, 4.347-8.424). Prostate cryosurgery was associated with longer PFS (HR 0.062, 95\% Cl, 0.048-.080).

Conclusions: CTC was a prognostic and treatment response marker for mPCA. ADT plus cryosurgery could reduce CTCs and prolong PFS vs. ADT alone in MPCA patients with low metastatic volume.

Keywords: Prostate cancer, Cryosurgery, Androgen deprivation therapy, Circulating tumor cell

\section{Introduction}

Androgen deprivation therapy (ADT) is the standard treatment for metastatic prostate cancer (mPCA). Previous studies showed that patients with $\mathrm{mPCA}$ could

\footnotetext{
*Correspondence: liuchx888@163.com

1 Department of Urology, Zhujiang Hospital, Southern Medical University, No. 253, Industrial Rd., Guangzhou, Guangdong Province 510282, People's Republic of China

Full list of author information is available at the end of the article
}

benefit from treatment of the primary tumor, including survival benefit or reduced incidence of local complications [1, 2]. The STAMPED trial [3] demonstrated improved overall survival (OS) with ADT plus prostate radiotherapy (RT) to the primary tumor vs. ADT alone only in patients with low-volume disease, but not in patients with high-volume disease. In a retrospective study, Si et al. [4] reported significant benefits in both $\mathrm{OS}$ and progress-free survival (PFS) in $\mathrm{mPCA}$ patients 
receiving cryosurgery plus ADT than ADT alone. However, there is no reliable marker to monitor treatment response (sensitivity to cryosurgery or ADT). The primary tumor could be a source of circulating tumor cells (CTCs); radical resection or intensified radiotherapy of the primary tumor in mPCA patients reduced the source of CTCs and improved the survival [5]. Recent studies indicate CTC count could predict the prognosis in patient with metastatic castration-resistant prostate cancer (mCRPC) [6-10]. Two prospective trials with abiraterone and chemotherapy $[10,11]$ showed that changes in CTCs as early as 4 weeks after treatment could identify patients who were not benefiting from treatment. The finding suggested that the CTC count could be an intermediate biomarker for overall survival in advanced mPCA. Up to date, there has been no study on CTCs in patients undergoing cryosurgery for mPCA. Therefore, the value of CTCs as a prognostic marker in patients undergoing cryosurgery for mPCA remains unclear. We hypothesized CTC count could identify patients with a poorer prognosis after treatment (cryosurgery or ADT) and predict treatment response in patients with mPCA. We conducted a retrospective study to compare CTC count and PFS in patients with $\mathrm{MPCA}$ receiving ADT plus cryosurgery versus ADT alone. The manuscript was prepared in accordance with the STROBE reporting checklist.

\section{Methods}

\section{Patients}

This study complied with the tenets of the Declaration of Helsinki (as was revised in 2013), and was approved by the Ethics Committee of Mindong Hospital Affiliated to Fujian Medical University on December 18, 2017 (Number \#0518-4). All patients undergoing either ADT plus cryosurgery (referred to as cryosurgery group below) or ADT alone (referred to as control group below) as initial therapy for prostate cancer with bone metastasis but no visceral metastasis at our clinic during a period from January 2015 to September 2017 were included in the retrospective analysis. Cryosurgery was recommended to all patients. The treatment (ADT alone vs. ADT plus cryosurgery) was based on patient choice. The criteria for inclusion in the analysis included (1) prostate cancer was confirmed by needle biopsy; (2) bone metastases were detected by nuclide bone scan and without super bone scan; (3) no visceral metastasis; (4) T stage $\leq$ cT3a; (5) presence of CTCs in peripheral blood before treatment, as defined by $\geqq 2$ CTCs in 5-ml blood using a CTC capture instrument NEXT CTC FS008 (NaoBio, China); (6) no previous local therapy; (7) prostate volume $\leq 50 \mathrm{ml}$. Informed consent was provided by either the patient or family member. The exclusion criteria included (1) emergence of mCRPC within 6 months after ADT. (2) Specific pathological types of prostate cancer other than acinar adenocarcinoma, including sarcoma, small cell carcinoma, and transitional cell carcinoma.

ADT consisted of 50-mg bicalutamide per day and subcutaneous injection of 3.75-mg leuprolide every month. Cryosurgery was performed by the same surgeon using the CRYO care system (Endocare Incorporated, USA). Briefly, patients were placed in a dorsal lithotomy position and received local infiltration anesthesia with $10-\mathrm{ml}$ $1 \%$ lidocaine. A urethral warming catheter was inserted into bladder to protect the urethra. 17-G cryoprobes were inserted under transrectal ultrasonography guidance and spaced approximately $1.0 \mathrm{~cm}$ apart. The cryoprobes were placed according to prostate size and shape, so that the entire prostatic gland was covered. Warm saline irrigation was conducted continuously to avoid urethral freezing. Two freeze-thaw cycles were conducted. Each freezing cycle lasted for 10-15 min. After surgery, the urethral warming unit was kept in place for 5 $\mathrm{min}$. The Foley catheter was removed 3 weeks later.

\section{Follow-up}

The follow-up was conducted every month during the first year, and every 3 months thereafter, and consisted of serum prostate specific antigen (PSA), testosterone, standard liver and kidney functional tests, and rectal digital examination. Prostate magnetic resonance imaging and nuclide bone scan were performed if progression (either biochemical or clinical) was suspected.

\section{Outcome measures}

Outcome measures included (1) demographics (age and gender) and clinical characteristics (prostate volume, PSA, biopsy Gleason score, clinical stage, and bone metastases count); (2) PFS; (3) CTC counts.

PFS was defined as the time from the initiation of ADT to the first evidence of biochemical or radiological progression. Biochemical progression was defined as three consecutive rises in PSA at least 1 week apart resulting in two $50 \%$ increases over the nadir, and a PSA $>2 \mathrm{ng} / \mathrm{ml}$. Radiological progression was defined as the appearance of new lesions: either two or more new bone lesions on bone scan or a soft tissue lesion using RECIST (response evaluation criteria in solid tumors). Symptomatic progression alone must be questioned and subject to further investigation.

CTCs were detected using a CTC capture instrument NEXT CTC FS008 (NaoBio Company, China) at baseline, 3 months and 12 months after treatment. Five milliliters of peripheral blood samples was collected and pretreated. CTCs were captured by Next CTC FS008 based on Nano microfluidics [12, 13]. Cell sorting utilizes the physical 
characteristics of large nucleocytoplasmic ratio and negative charge on the surface of CTCs. The captured cells were identified as CTCs by fluorescence in situ hybridization (FISH). Cells with the signal in nucleus $\geq 3$ triploid, positive DAPI, and negative CD45 were considered CTCs.

\section{Statistical analysis}

Continuous variables were analyzed with Student's $t$ test for independent samples. Categorical variables were analyzed using chi square test. Ranked variables were analyzed using the Wilcoxon rank sum test. PFS was analyzed using Kaplan-Meier analysis followed by a log-rank test. Cox proportional hazards regression was conducted to identify variables associated with PFS. In addition to the main analysis, we conducted subgroup analyses based on metastatic volume. High metastatic volume was defined as $\geq 4$ bone metastatic lesions that included at least 1 outside the vertebral column [5]; the others were considered as low metastatic volume. Statistical significance was defined as $p<0.05$ (2-sided). All analyses were performed using the SPSS20.0 statistical software ((IBM Corp., Armonk, NY, USA).

\section{Results}

Baseline patient characteristics

A total of 43 patients were included in the analysis. Twenty patients received cryosurgery plus ADT, and the remaining 23 received ADT only. Mean age was $70.3 \pm$ 7.5 years (range, 55-83) in the cryosurgery group and $68.7 \pm 7.2$ years (range, 56-84) in the control group ( $p=$ 0.479 ; Table 1 ). The 2 groups did not differ significantly in serum PSA, biopsy Gleason score, clinical stage, and bone metastases count. Median CTC count was 4 (IQR, $3-6)$ in the cryosurgery group and 6 (IQR, 3-7) in the control group $(p=0.475)$.

\section{Complications after cryosurgery}

Surgery was completed in all 20 patients who opted to receive cryosurgery. The average operative time was 93.3 $\pm 12.1 \mathrm{~min}$. Urinary tract infection was noted in 7 (35\%) patients, but dissipated by empirical antibiotic therapy. No urinary incontinence, urethra injury, rectal injury, and recto-urethral fistulas occurred. All patients could urinate at will after removing the catheter at 3 weeks after surgery.

\section{Oncological outcomes}

The median follow-up was 32 months (range, 22-36) in the control group and 36 months (range, 26-38) in the cryosurgery group. During the follow-up period, two $(8.70 \%)$ patients in the control group died of myocardial infarction; two patients developed only radiological
Table 1 Demographic and baseline characteristics

\begin{tabular}{|c|c|c|c|}
\hline & ADT alone, $n=23$ & $\begin{array}{l}\text { ADT }+ \\
\text { cryosurgery, } \\
n=20\end{array}$ & $p$ \\
\hline Age (years), mean $\pm S D$ & $68.7 \pm 7.2$ & $70.3 \pm 7.5$ & 0.479 \\
\hline$\leq 60, n(\%)$ & $3(13.0 \%)$ & $2(10 \%)$ & 0.716 \\
\hline $60-70, n(\%)$ & $14(60.9 \%)$ & $12(60 \%)$ & \\
\hline$>70, \mathrm{n}(\%)$ & $6(26.1 \%)$ & $6(30 \%)$ & \\
\hline PSA $(n g / m l)$, mean $\pm S D$ & $84.16 \pm 27.45$ & $84.83 \pm 31.77$ & 0.074 \\
\hline \multicolumn{4}{|l|}{ Biopsy Gleason score, $n(\%)$} \\
\hline$\leq 6$ & $1(4.3 \%)$ & $2(10 \%)$ & 0.615 \\
\hline 7 & $8(34.8 \%)$ & $7(35 \%)$ & \\
\hline$\geq 8$ & $14(60.9 \%)$ & $11(55 \%)$ & \\
\hline $\begin{array}{l}\text { Prostate volume }(\mathrm{ml}) \text {, mean } \\
\pm \mathrm{SD}\end{array}$ & $42.00 \pm 3.73$ & $42.30 \pm 4.24$ & 0.806 \\
\hline \multicolumn{4}{|l|}{ Clinical T stage, $n(\%)$} \\
\hline$\leq \mathrm{cT} 2 \mathrm{~b}$ & $8(34.8 \%)$ & $5(25 \%)$ & 0.555 \\
\hline CT2C & $10(43.5 \%)$ & $10(50 \%)$ & \\
\hline сT3a & $5(21.7 \%)$ & $5(25 \%)$ & \\
\hline \multicolumn{4}{|l|}{ Lymph nodes status, $n$ (\%) } \\
\hline No & $18(78.3 \%)$ & $15(75 \%)$ & 0.801 \\
\hline N1 & $5(21.7 \%)$ & $5(25 \%)$ & \\
\hline \multicolumn{4}{|l|}{ Bone metastases count, $n(\%)$} \\
\hline$\leq 3$ & $10(43.5 \%)$ & $11(55 \%)$ & 0.451 \\
\hline$>3$ & $13(56.5 \%)$ & $9(45 \%)$ & \\
\hline CTCs count, median (IQR) & $6(3-7)$ & $4(3-6)$ & 0.475 \\
\hline
\end{tabular}

$A D T$ androgen deprivation therapy, CTC circulating tumor cell, IQR interquartile range, $P S A$ prostate specific antigen, $S D$ standard deviation

progression (Fig. 1A, B), and 19 patients developed PSA progression. In terms of subsequent therapy in patients with $\mathrm{mCRPC}(n=21), 5$ patients $(23.8 \%)$ had no secondline treatment, 10 patients $(47.6 \%)$ received abiraterone, and 6 patients $(28.6 \%)$ received chemotherapy with docetaxel. In the cryosurgery group, two (10\%) patients died of myocardial infarction and $1(5 \%)$ patient died of stroke; one patient developed only radiological progression (Fig. 1C), and 16 patients developed PSA progression. In terms of subsequent therapy in patients with mCRPC ( $n$ $=17), 3(17.6 \%)$ patients had no second-line treatment, 9 (52.9\%) patients received abiraterone and 5 (29.4\%) patients received chemotherapy with docetaxel.

The median PFS was 35 months [interquartile range (IQR) 33-37] in the cryosurgery group vs. 30 months (IQR 27-32) in the control group ( $p<0.001$, Fig. 2A). In the multivariate Cox regression, shorter PFS was independently associated with the following variables: baseline PSA $\geq 100 \mathrm{ng} / \mathrm{ml}$ [hazard rate (HR) 6.584, 95\% CI, 5.309-8.166], biopsy Gleason score $\geqq 8$ (HR 2.064, 95\% CI, 1.608-2.650), clinic T stage > T2b (HR 5.021, 95\% $\mathrm{CI}, 3.925-6.421)$, number of bone metastases $>3$ (HR 3.421, 95\% CI, 2.786-4.202), positive CTCs at 3 months 
a

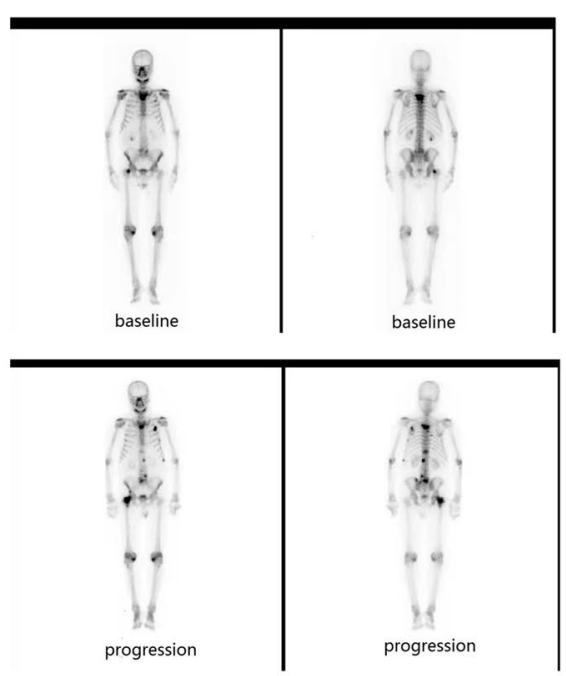

b
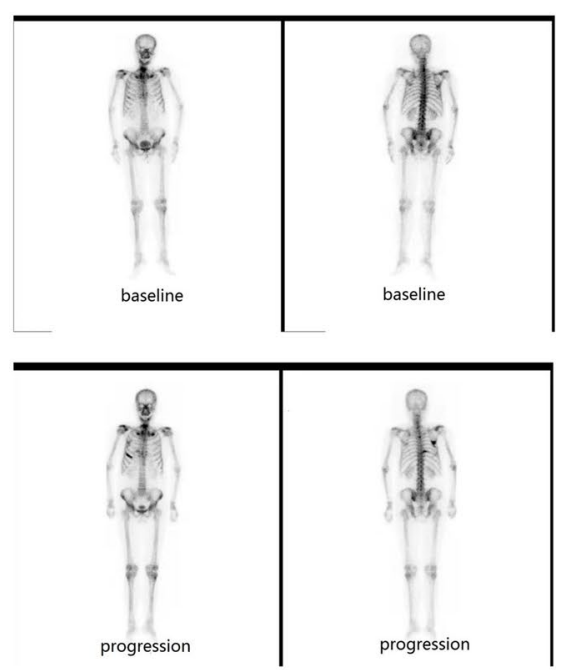

C
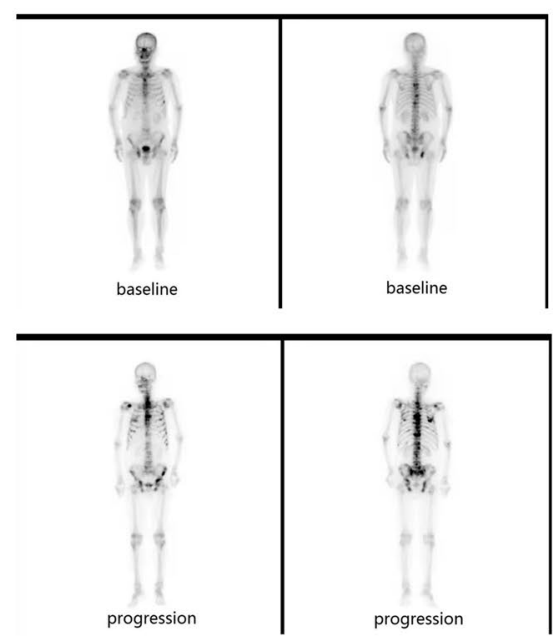

Fig. 1 A Nuclide bone scan image of case 1 in the control: baseline vs. radiological progression. B Nuclide bone scan image of case 2 in the control: baseline vs. radiological progression. C Nuclide bone scan image of case 1 in the ADT plus cryosurgery group: baseline vs. radiological progression

post-treatment (HR 6.833, 95\% CI, 5.176-9.022), positive CTCs 1 year post-treatment (HR 6.051, 95\% CI, 4.347-8.424). Prostate cryosurgery was associated with longer PFS (HR 0.062, 95\% CI, 0.048-.080) (Table 2).

\section{CTC count}

CTC count was significantly lower in the cryosurgery group at both 3 months $(z=2.170, p=0.030)$ and 12 months $(z=2.481 ; p=0.013)$. The percentage of patients with $>5$ CTCs per 5 -ml peripheral blood was lower in the cryosurgery group at both $3(15.5 \%$ vs. $43.5 \%, p=0.030$ ) and 12 months (0 vs. $30.4 \%, p$ $=0.013$ ) (Table 3). In comparison to the baseline, the number of CTCs at both 3 and 12 months was lower in the cryosurgery group ( $p=0.004$ and $p<0.001$, respectively), but not in the ADT alone group.

\section{Subgroup analysis}

Among the 43 patients, 21 patients had low metastatic volume, and 22 patients had high metastatic volume. In the 21 patients with low metastatic volume, 11 received ADT plus cryosurgery group, and the remaining 10 received ADT alone. In the 22 patients with high metastatic volume, 9 patients received ADT plus cryosurgery, and the remaining 13 received ADT alone. Median baseline bone metastases count was 2 (IQR $1-3)$ vs. 8 (IQR 6-11) in patients with low vs. high metastatic volume $(p<0.001)$. Median baseline CTC count was 3 (IQR 3-4) vs. 7 (IQR 6-8) in patients with low vs. high metastatic volume $(p<0.001)$.

In the subgroup analysis that included the 21 patients with low metastatic volume only, CTC count was significantly lower in the cryosurgery group at both 3 months $(z=1.969, p=0.049)$ and 12 months $(z=2.622, p=$ 0.009) (Table 4). The median PFS was 37 months (IQR 35-37) in cryosurgery vs. 30 months (IQR 27-32) in the control group ( $p=0.004$; Fig. $2 \mathrm{~B})$.

In the subgroup analysis that included the 22 patients with high metastatic volume only, CTC count did not differ between the 2 groups at any time point (Table 5). The median PFS was 33 months (IQR 28-35) in cryosurgery vs. 29 months (IQR 24-32) in the control group $(p=0.076$; Fig. 2C). 


\section{Discussion}

Consistent with a previous study by $\mathrm{Si}$ et al. [4], the current study demonstrated longer PFS in the patients receiving ADT plus surgery for mPCA than ADT alone. Of note, we found survival benefit for ADT plus cryosurgery only in patients with low metastatic volume, but not high metastatic volume. In the STAMPEDE trial [3], radiotherapy to the primary tumor did not improve OS in the overall study population. In the subgroup analysis that divided the patients based on the CHAARTED standard, however, radiotherapy increased the OS in the low-volume subgroup. Results in subgroup analysis in our study were consistent with the STAMPED study.

Cox multivariate analysis showed that the patients with positive CTCs at 3 months or 1 year post-treatment had shorter PFS. In the IMMC38 trial, de Bono et al. [7] detected CTCs in 231 CRPC patients receiving chemotherapy with CellSearch system, and showed a close association between shorter OS with higher CTC at both prior to and after treatment. Mandel et al. [14] examined CTCs in 33 patients with hormone-naïve oligometastatic prostate cancer undergoing cytoreductive radical prostatectomy, and found earlier CRPC and shorter OS in patients with CTCs $\geq 2$ in 7.5 - $\mathrm{ml}$ peripheral blood at 6 months postoperatively. The results suggest that high CTC is a risk for poor prognosis, and maybe helpful in selecting hormone-naïve oligometastatic prostate cancer patients for cytoreductive radical prostatectomy. The patients with lower CTCs were suitable candidate for cytoreductive radical prostatectomy. To our best knowledge, this is the first study which found CTC count could identify patients with a poorer prognosis after treatment (cryosurgery or ADT). The patients with positive CTCs at 3 months or 1 year post-treatment had poorer prognosis after treatment (cryosurgery or ADT).

Our study also showed CTC count could determine the degree of response to the treatment. In the current study, the patients receiving ADT plus cryosurgery had lower CTCs at 3 months and 1 year after treatment, and longer PFS than those receiving ADT alone. In comparison to the baseline, the number of CTCs at both 3 and 12 months was lower in the cryosurgery group, but not in the ADT alone group. Lower CTCs in the patients receiving ADT plus cryosurgery was evident in the subgroup analysis that included patients with low metastatic volume only, but not in the subgroup that included the patients with high metastatic volume. Such a finding is consistent with the survival benefit in patients with low metastatic volume only. These results suggested in the patients with low metastatic volume, those receiving ADT plus cryosurgery had lower CTCs and responded better to the treatment than those receiving ADT alone. No similar effect was found in the patients with high metastatic volume.

The higher number of CTCs might be associated with advanced clinical stage and higher metastatic volume [15]. The positive rate of CTCs detected by CellSearch system was $0-10 \%$ in healthy volunteers $[16,17], 5-38.4 \%$ in non-metastatic high risk prostate cancer patients [16-19], $48.5 \%$ in oligometastatic prostate cancer [14], and $80 \%$ in patients with mCRPC [20]. In our study, the number of CTCs was significantly higher in the patients with high metastatic volume. Because CTCs most likely represent an aggressive pool of cells with the potential to form metastases, the patient with higher CTCs might develop more bone metastases. The patients with high bone metastases might have more source of CTCs and have higher CTCs. But our hypothesis still needs to be tested and the mechanism remains unclear. There was limited study to assess the association of CTC counts with bone metastases volume. In a previous study of 19 metastatic patients with only bone metastases (mCRPC and metastatic taxane-refractory) [17], no correlation was observed between CTC counts and osseous tumor burden assessed by bone lesion count or bone scan index. Such a difference may reflect different patient characteristics (hormone-sensitive in the current study vs. $\mathrm{mCRPC}$ and metastatic taxane-refractory in previous study).

CTCs could derive from either primary tumor or metastatic foci. We hypothesize that since primary tumor represents the major source of CTCs in patients with low metastatic volume, resection of the primary tumor could decrease the number of CTCs, and could be helpful in disease control. In contrast, contribution of the primary tumor to CTCs is relatively small. As a result, the impact of local treatment for primary tumor on patient survival is minimal.

Satkunasivam et al. [5] summarized the mechanisms of survival benefits from local therapy (radical prostatectomy or radiotherapy). First, eradication of the primary tumor eliminates the source of cytokine signaling that prepares niches for eventual sites of metastases and promotes their growth [21]. Second, the primary tumor may remain a source of CTCs that are capable of "self-seeding" the primary organ [22]. Third, local therapy may reduce the number of self-renewing cells that persist after ADT due to the low levels of immature androgen receptors [23]. Local treatment against

(See figure on next page.)

Fig. 2 A Progression-free survival: a comparison between ADT plus cryosurgery $(n=20)$ vs. ADT alone $(n=23)$. B Sub-group analysis of progression-free survival in the patients with low metastatic volume: a comparison between ADT plus cryosurgery $(n=11)$ vs. ADT alone $(n=10)$. C Sub-group analysis of progression-free survival in the patients with high metastatic volume: a comparison between ADT plus cryosurgery $(n=9)$ vs. ADT alone $(n=13)$ 


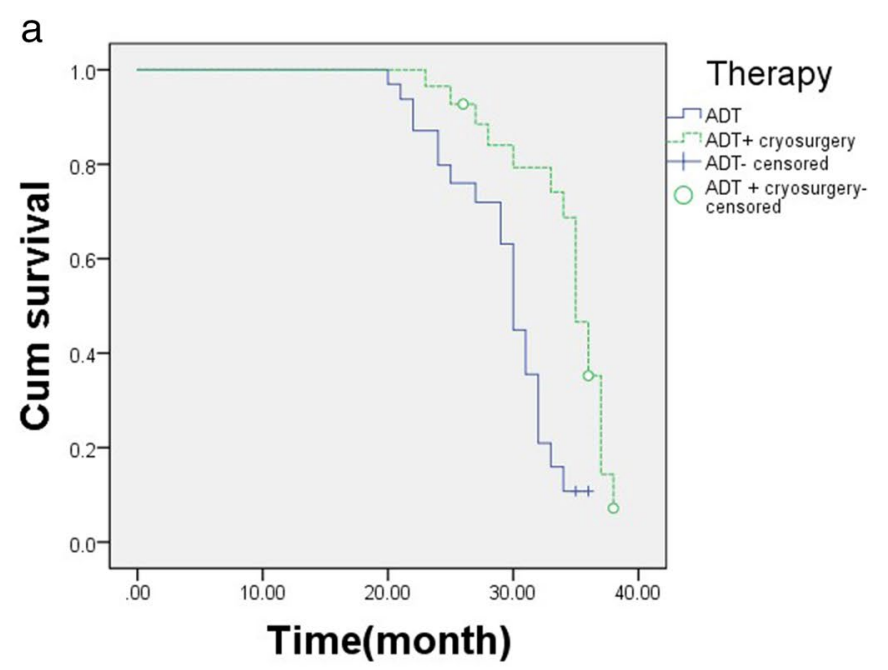

b

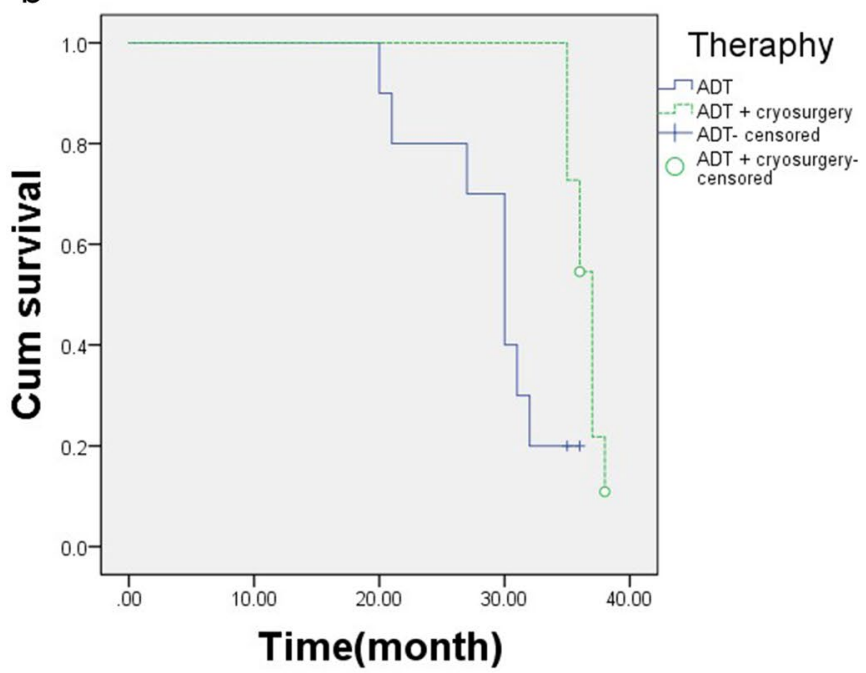

C

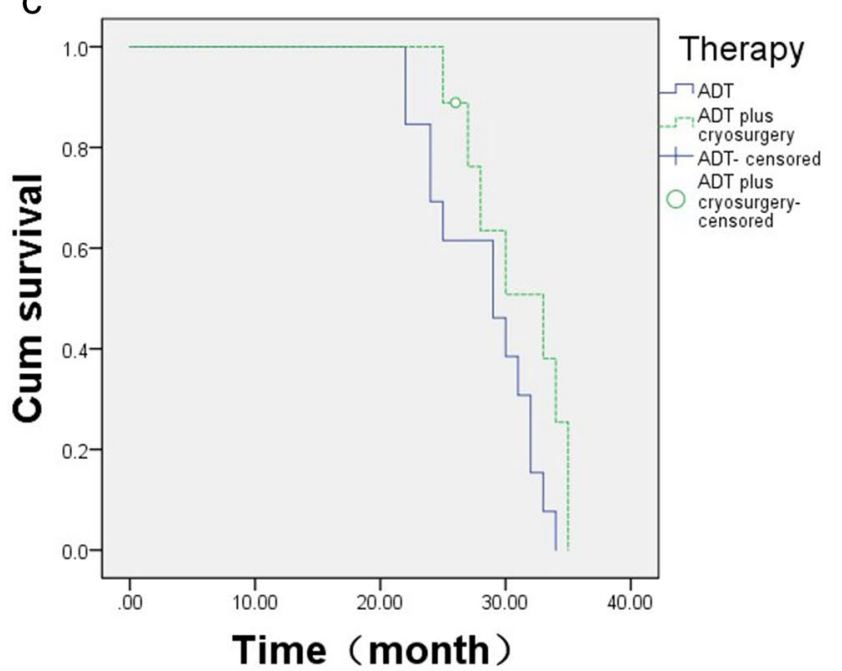

Fig. 2 (See legend on previous page.) 
Table 2 Multivariate Cox regression of progression-free survival

\begin{tabular}{|c|c|c|c|}
\hline Variable & Hazards ratio & $95 \% \mathrm{Cl}$ & $P$ value \\
\hline $\begin{array}{l}\text { Prostate cryosurgery (vs. ADT } \\
\text { alone) }\end{array}$ & 0.062 & $0.048-0.080$ & $<0.001$ \\
\hline $\mathrm{PSA} \geq 100 \mathrm{ng} / \mathrm{ml}(\mathrm{vs} .<100 \mathrm{ng} / \mathrm{ml})$ & 6.584 & $5.309-8.166$ & $<0.001$ \\
\hline Gleason score $\geq 8$ (vs.<8) & 2.064 & $1.608-2.650$ & $<0.001$ \\
\hline Clinical T stage $>$ T2b (vs. $\leq \mathrm{T} 2 \mathrm{~b})$ & 5.021 & $3.925-6.421$ & $<0.001$ \\
\hline $\begin{array}{l}\text { Bone metastases count }>3 \text { (vs. } \leq \\
\text { 3) }\end{array}$ & 3.421 & $2.786-4.202$ & $<0.001$ \\
\hline $\begin{array}{l}\text { Positive CTCs at 3-month (vs. } \\
\text { negative) }\end{array}$ & 6.833 & $5.176-9.022$ & $<0.001$ \\
\hline $\begin{array}{l}\text { Positive CTCS at 1-year (vs. nega- } \\
\text { tive) }\end{array}$ & 6.051 & $4.347-8.424$ & $<0.001$ \\
\hline
\end{tabular}

Cl confidence interval, CTC circulating tumor cell, PSA prostate specific antigen

Table 3 Number/percentage of the patients with different number of CTCs count at baseline, 3 months, and 12 months after treatment

\begin{tabular}{|c|c|c|c|c|}
\hline & ADT alone, $n=23$ & $\begin{array}{l}\text { ADT + } \\
\text { cryosurgery, } n \\
=20\end{array}$ & $Z$ value & $P$ value \\
\hline \multicolumn{5}{|c|}{ Baseline, $n(\%)$} \\
\hline$<2$ & $0(0 \%)$ & $0(0 \%)$ & 0.789 & 0.430 \\
\hline $2-5$ & $11(47.8 \%)$ & $12(60 \%)$ & & \\
\hline$\geq 5$ & $12(52.2 \%)$ & $8(40 \%)$ & & \\
\hline \multicolumn{5}{|c|}{3 months, $n$ (\%) } \\
\hline$<2$ & $4(17.4 \%)$ & $8(40 \%)$ & 2.170 & 0.030 \\
\hline $2-5$ & $9(39.1 \%)$ & $9(45 \%)$ & & \\
\hline$\geq 5$ & $10(43.5 \%)$ & $3(15 \%)$ & & \\
\hline \multicolumn{5}{|c|}{12 months, $n$ (\%) } \\
\hline$<2$ & $9(39.1 \%)$ & $14(70 \%)$ & 2.481 & 0.013 \\
\hline $2-5$ & 7 (30.4\%) & $6(30 \%)$ & & \\
\hline$\geq 5$ & 7 (30.4\%) & $0(0 \%)$ & & \\
\hline
\end{tabular}

$A D T$ androgen deprivation therapy

the primary tumor may induce inflammatory reaction and promote antigen production, which in turn could induce anti-tumor immune responses. Therefore, removal of the primary tumor may reduce metastases $[23,24]$. Cryosurgery ablates tumors in situ, leading to the release of tumor proteins and intact tumor associated antigens. Residual tumor antigens may activate anti-tumor immune response in the inflammatory microenvironment [25]. Our current study confirmed that prostate cryosurgery could reduce the source and number of CTCs and then prolong PFS.

The current study has several limitations. As a retrospective analysis, this study has inherent bias in patient selection. Second, small sample size is an important limitation in the current study. As such, the results must be considered preliminary despite of the statistically significant differences between the two groups. Third, the
Table 4 Sub-group analysis of CTC count in patients with low metastatic volume

\begin{tabular}{|c|c|c|c|c|}
\hline & ADT alone, $n=10$ & $\begin{array}{l}\text { ADT + } \\
\text { cryosurgery, } n \\
=11\end{array}$ & $Z$ value & $P$ value \\
\hline \multicolumn{5}{|c|}{ Baseline, $n(\%)$} \\
\hline$<2$ & $0(0 \%)$ & $0(0 \%)$ & 0.000 & 1.000 \\
\hline $2-5$ & $10(100 \%)$ & $11(100 \%)$ & & \\
\hline$\geq 5$ & $0(0 \%)$ & $0(0 \%)$ & & \\
\hline \multicolumn{5}{|c|}{3 months, $n$ (\%) } \\
\hline$<2$ & $2(20 \%)$ & $7(63.6 \%)$ & 1.969 & 0.049 \\
\hline $2-5$ & $8(80 \%)$ & $4(36.4 \%)$ & & \\
\hline$\geq 5$ & $0(0 \%)$ & $0(0 \%)$ & & \\
\hline \multicolumn{5}{|c|}{12 months, $n(\%)$} \\
\hline$<2$ & $5(50 \%)$ & $11(100 \%)$ & 2.622 & 0.009 \\
\hline $2-5$ & $5(50 \%)$ & $0(0 \%)$ & & \\
\hline$\geq 5$ & $0(0 \%)$ & $0(0 \%)$ & & \\
\hline
\end{tabular}

$A D T$ androgen deprivation therapy

Table 5 Sub-group analysis of CTCs count in patients with high metastatic volume

\begin{tabular}{|c|c|c|c|c|}
\hline & ADT alone, $n=13$ & $\begin{array}{l}\text { ADT }+ \\
\text { cryosurgery, } \\
n=9\end{array}$ & $Z$ value & $P$ value \\
\hline \multicolumn{5}{|c|}{ Baseline, $n(\%)$} \\
\hline$<2$ & $0(0 \%)$ & $0(0 \%)$ & 0.000 & 1.000 \\
\hline $2-5$ & $0(0 \%)$ & $0(0 \%)$ & & \\
\hline$\geq 5$ & $13(100 \%)$ & $9(100 \%)$ & & \\
\hline \multicolumn{5}{|c|}{3 months, $n$ (\%) } \\
\hline$<2$ & $2(15.4 \%)$ & $1(11.1 \%)$ & 1.596 & 0.111 \\
\hline $2-5$ & $1(7.7 \%)$ & $5(55.6 \%)$ & & \\
\hline$\geq 5$ & 10 (76.9\%) & $3(33.3 \%)$ & & \\
\hline \multicolumn{5}{|c|}{12 months, $n$ (\%) } \\
\hline$<2$ & $4(30.8 \%)$ & $3(33.3 \%)$ & 1.593 & 0.111 \\
\hline $2-5$ & $2(15.4 \%)$ & $6(66.7 \%)$ & & \\
\hline$\geq 5$ & 7 (53.8\%) & $0(0 \%)$ & & \\
\hline
\end{tabular}

$A D T$ androgen deprivation therapy

follow-up was relatively short; we therefore did not analyze cancer-specific survival and OS.

\section{Conclusions}

In summary, CTC was a prognostic and treatment response marker in patients undergoing androgen deprivation therapy (ADT) plus cryosurgery or ADT alone for mPCA. ADT plus cryosurgery could reduce CTCs and prolong PFS vs. ADT alone in mPCA patients with low metastatic volume. 


\section{Abbreviations}

ADT: Androgen deprivation therapy; mPCA: Metastatic prostate cancer; OS: Overall survival; RT: Radiotherapy; PFS: Progress-free survival; CTCs: Circulating tumor cells; mCRPC: Metastatic castration-resistant prostate cancer; PSA: Prostate specific antigen; IQR: Interquartile range; HR: Hazard rate.

\section{Acknowledgements}

None.

\section{Authors' contributions}

(I) Conception and design: Chunxiao Liu; (II) Administrative support: Mingxiong Sheng; (III) Provision of study materials or patients: Mingxiong Sheng; (IV) Collection and assembly of data: Shanming Guo; (V) Data analysis and interpretation: Mingxiong Sheng, Shanming Guo; (VI) Manuscript writing: All authors; (VII) Final approval of manuscript: All authors.

\section{Funding}

This work was supported by the Natural Science Foundation of Fujian Province, China (No. 2018J01216).

\section{Availability of data and materials}

The datasets used and/or analyzed during the current study are available from the corresponding author on reasonable request.

\section{Declarations}

\section{Ethics approval and consent to participate}

This study was approved by the Ethics Committee of Mindong Hospital Affiliated to Fujian Medical University on December 18, 2017 (Number \#0518-4). Informed consent was provided by either the patient or family member.

\section{Consent for publication}

We declare that all patients have signed an informed consent form which state that the details/images will be freely available on the internet and may be seen by the general public.

\section{Competing interests}

The authors declare that they have no competing interests.

\section{Author details}

${ }^{1}$ Department of Urology, Zhujiang Hospital, Southern Medical University, No. 253, Industrial Rd., Guangzhou, Guangdong Province 510282, People's Republic of China. ${ }^{2}$ Department of Urology, Mindong Hospital affiliated to Fujian Medical University, Fuan, Fujian Province 355000, People's Republic of China.

Received: 5 September 2021 Accepted: 23 November 2021

Published online: 13 December 2021

\section{References}

1. Slaoui A, Albisinni S, Aoun F, Assenmacher G, Al Hajj Obeid W, Diamand R, et al. A systematic review of contemporary management of oligometastatic prostate cancer: fighting a challenge or tilting at windmills? World J Urol. 2019;37(11):2343-53.

2. Jenjitranant $P$, Touijer KA. Role of surgery in oligometastatic prostate cancer. Prostate Int. 2019:7(4):125-30.

3. Parker CC, James ND, Brawley CD, Clarke NW, Hoyle AP, Ali A, et al. Radiotherapy to the primary tumour for newly diagnosed, metastatic prostate cancer (STAMPEDE): a randomised controlled phase 3 trial. Lancet. 2018;392(10162):2353-66.

4. Si T, Guo Z, Yang X, Zhang W, Xing W. The oncologic results of cryoablation in prostate cancer patients with bone metastases. Int J Hyperthermia. 2018;34(7):1044-8.

5. Satkunasivam R, Kim AE, Desai M, Nguyen MM, Quinn Dl, Ballas L, et al. Radical prostatectomy or external beam radiation therapy vs no local therapy for survival benefit in metastatic prostate cancer: A SEER-Medicare analysis. J Urol. 2015;194(2):378-85.
6. Masuda T, Hayashi N, Iguchi T, Ito S, Eguchi H, Mimori K. Clinical and biological significance of circulating tumor cells in cancer. Mol Oncol. 2016:10(3):408-17.

7. de Bono JS, Scher HI, Montgomery RB, Parker C, Miller MC, Tissing H, et al. Circulating tumor cells predict survival benefit from treatment in metastatic castration-resistant prostate cancer. Clin Cancer Res. 2008;14(19):6302-9.

8. Olmos D, Arkenau H, Ang JE, Ledaki I, Attard G, Carden CP, et al. Circulating tumour cell (CTC) counts as intermediate end points in castrationresistant prostate cancer (CRPC): a single-centre experience. Ann Oncol. 2009;20(1):27-33.

9. Scher HI, Jia X, de Bono JS, Fleisher M, Pienta KJ, Raghavan D, et al. Circulating tumour cells as prognostic markers in progressive, castrationresistant prostate cancer: a reanalysis of IMMC38 trial data. Lancet Oncol. 2009;10(3):233-9.

10. Heller G, McCormack R, Kheoh T, Molina A, Smith MR, Dreicer R, et al. Circulating tumor cell number as a response measure of prolonged survival for metastatic castration-resistant prostate cancer: a comparison with prostate-specific antigen across five randomized phase III clinical trials. J Clin Oncol. 2018;36(6):572-80.

11. Lorente D, Olmos D, Mateo J, Bianchini D, Seed G, Fleisher M, et al. Decline in circulating tumor cell count and treatment outcome in advanced prostate Cancer. Eur Urol. 2016;70(6):985-92.

12. Dong Y, Skelley AM, Merdek KD, Sprott KM, Jiang C, Pierceall WE, et al. Microfluidics and circulating tumor cells. J Mol Diagn. 2013;15(2):149-57.

13. Burinaru TA, Avram M, Avram A, Mărculescu C, Țîncu B, Țcureanu V, et al. Detection of circulating tumor cells using microfluidics. ACS Comb Sci. 2018;20(3):107-26.

14. Mandel PC, Huland $H$, Tiebel A, Haese A, Salomon G, Budäus L, et al. Enumeration and changes in circulating tumor cells and their prognostic value in patients undergoing cytoreductive radical prostatectomy for oligometastatic prostate cancer-translational research results from the prospective ProMPT trial. Eur Urol Focus. 2021;7(1):55-62.

15. Pantel K, Hille C, Scher HI. Circulating tumor cells in prostate cancer: from discovery to clinical utility. Clin Chem. 2019;65(1):87-99.

16. Resel Folkersma L, San José Manso L, Galante Romo I, Moreno Sierra J, Olivier GC. Prognostic significance of circulating tumor cell count in patients with metastatic hormone-sensitive prostate cancer. Urology. 2012;80(6):1328-32.

17. Thalgott M, Rack B, Maurer T, Souvatzoglou M, Eiber M, Kreß V, et al. Detection of circulating tumor cells in different stages of prostate cancer. J Cancer Res Clin Oncol. 2013;139(5):755-63.

18. Kuske A, Gorges TM, Tennstedt P, Tiebel AK, Pompe R, Preißer F, et al. Improved detection of circulating tumor cells in non-metastatic high-risk prostate cancer patients. Sci Rep. 2016;6:39736.

19. Loh J, Jovanovic L, Lehman M, Capp A, Pryor D, Harris M, et al. Circulating tumor cell detection in high-risk non-metastatic prostate cancer. J Cancer Res Clin Oncol. 2014;140(12):2157-62.

20. Liu W, Yin B, Wang X, Yu P, Duan X, Liu C, et al. Circulating tumor cells in prostate cancer: precision diagnosis and therapy. Oncol Lett. 2017;14(2):1223-32

21. Psaila B, Lyden D. The metastatic niche: adapting the foreign soil. Nat Rev Cancer. 2009:9(4):285-93.

22. Kim MY, Oskarsson T, Acharyya S, Nguyen DX, Zhang XH, Norton L, et al. Tumor self-seeding by circulating cancer cells. Cell. 2009;139(7):1315-26.

23. Stoyanova T, Cooper AR, Drake JM, Liu X, Armstrong AJ, Pienta KJ, et al. Prostate cancer originating in basal cells progresses to adenocarcinoma propagated by luminal-like cells. Proc Natl Acad Sci U S A. 2013;110(50):20111-6.

24. Zelefsky MJ, Reuter VE, Fuks Z, Scardino P, Shippy A. Influence of local tumor control on distant metastases and cancer related mortality after external beam radiotherapy for prostate cancer. J Urol. 2008;179(4):136873 discussion 1373.

25. Sabel MS. Cryo-immunology: a review of the literature and proposed mechanisms for stimulatory versus suppressive immune responses. Cryobiology. 2009;58(1):1-11.

\section{Publisher's Note}

Springer Nature remains neutral with regard to jurisdictional claims in published maps and institutional affiliations. 